\title{
Qualitative Analysis of Risk for Safety Belt Testing Equipment
}

\author{
Magdalena BARBU \\ Transilvania University of Brasov, Romania, magda.n@unitbv.ro \\ Catrina CHIVU \\ Transilvania University of Brasov, Romania, catrina.c@unitbv.ro
}

\begin{abstract}
Organizations of all types and sizes face a number of risks that may affect the achievement of their goals. These goals can relate to a range of organization activities, from strategic initiatives to operations, processes, and projects. Risk assessment provides decision-makers and responsible parties with a better understanding of the risks that could affect the achievement of the objectives. The paper presents the main method to be used in risk assessment, namely risk analysis. It provides a basis for deciding on the most appropriate approach to be used to address the risks.
\end{abstract}

\section{Keywords}

risk, safety, standards, risk management, risk assessment methods-technique

\section{Introduction}

In any area of economic, social or political activity, there is the problem of the risk that may arise, with consequences that cannot always be predicted or anticipated.

Risk assessment and modeling is a complex activity, involving multidisciplinary approaches from different branches of science, namely knowledge from the economic, technological, sociological or political domains. The results of the risk assessment have a decisive influence on the decisions and the success of the strategies adopted at the macro and microeconomic level.

The stages of the risk management process as presented in the literature are: setting objectives, identifying risks, risk analysis, risk assessment, establishing and implementing an appropriate risk response strategy (risk treatment), communication and consultation, and monitoring or review.

Risk analysis consists of determining the consequences and their probabilities for identified risk events, considering the presence (or not) and the effectiveness of any existing controls. The consequences and their probabilities are then combined to determine the level of risk [1].

Two major categories are distinguished in the risk analysis process: qualitative risk analysis and quantitative risk analysis. The results of the qualitative risk analysis are less accurate, they are more indicative than precise. If these results are not satisfactory, risk management also provides a quantitative analysis showing results in numerical form as a result of the calculations made.

\section{Model of Qualitative Analysis of Risk for Safety Belt Testing Equipment}

Qualitative analysis is an important step in the risk management process, which involves the following steps (Figure 1):

- the choice of risk and probability scales;

- establishment of the risk reference matrix;

- determining the risk score and the risk matrix;

- the ranking of risks.

Qualitative risk analysis process is shown in Figure 1.

Qualitative risk analysis includes several techniques: scenario technique and probability-impact matrix technique [2].

The technique of scenarios involves the formation of a group of informed people, specialists in the field, who are required to apply their knowledge and imagination to describe one or more possible ways of carrying out an event from a situation concrete. 


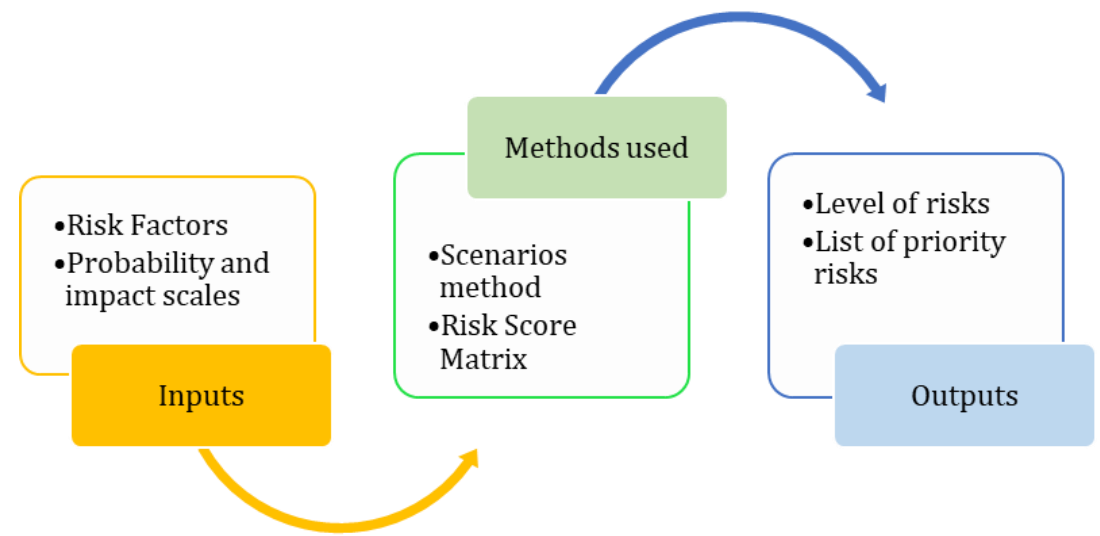

Fig. 1. Qualitative risk analysis process

Probability-impact matrix technique is a technique that combines the two components of the risk thus presenting an overall image.

\subsection{Identification of risk factors}

As a result of the assessment of the existing situation, factors that may influence the likelihood and impact of the risk, respectively, can contribute to increased risks of obtaining invalid safety belt tests have been identified (Table 1).

Table 1. Risk Factors

\begin{tabular}{|l|l|}
\hline$R_{i}$ & \\
\hline$R 1$ & Improper use of equipment \\
\hline R2 & Use of equipment by unauthorized personnel \\
\hline R3 & Performing incorrect tests \\
\hline R4 & Failure to follow the instructions for use of the equipment \\
\hline R5 & Overload of equipment \\
\hline R6 & Fatigue \\
\hline R7 & Unergonomic working position \\
\hline R8 & Use of uncalibrated equipment \\
\hline R9 & Noise \\
\hline R10 & Low reliability degree \\
\hline R11 & Hard to exploit \\
\hline R12 & Improper temperature \\
\hline R13 & High humidity \\
\hline R14 & Positioning of equipment in too small space \\
\hline R15 & Positioning of equipment in a poorly illuminated space \\
\hline R16 & Incomplete working method \\
\hline R17 & Failure to observe the order of operations \\
\hline R18 & Application of improper force on the material \\
\hline
\end{tabular}

\subsection{Determination of probability and impact scales}

Risk analysis by means of probability and impact helps to identify those risk factors that have a high score and to adopt the appropriate treatment which may be acceptance, mitigation or elimination [3].

The probability scale of risk (Table 2) can be made up of two categories of values, namely: -ordinal values, respectively very low (almost impossible), low (unlikely), medium (possible), high (probable) and very high (almost safe);

-cardinal values, in which case the above ratings are assigned probability scores, respectively 1, 2, 3, 4 and 5 , in which 1 is the score for a risk that has a very low probability of occurrence, and 5 is the score of a risk that has high probability of occurrence. 
RECENT, Vol. 19, no. 3(56), December, 2018

Table 2. Probability scale of risk

\begin{tabular}{|l|l|c|}
\hline $\begin{array}{c}\text { Qualitative assessment of } \\
\text { probability }\end{array}$ & $\begin{array}{c}\text { Quantitative assessment of } \\
\text { probability }\end{array}$ & Probability score \\
\hline Very high (very probable) & Once in 3 months & 5 \\
\hline High (probable) & Once in 6 months & 4 \\
\hline Medium & Once a year & 3 \\
\hline Low (unlikely) & Once in 3 years & 2 \\
\hline Very low (very unlikely) & More than 3 years & 1 \\
\hline
\end{tabular}
be:

The risk impact scale (Table 3) reflects the severity of the damage, in case of risk occurrence and may

-ordinary, with impact values: very low, low, moderate, high, very high;

-cardinal, with the values of impact scores 1, 2, 5, 10 and 20, in which the value of 1 represents the score for a very low impact and 20 for a very high impact.

Table 3. Risk Impact Scale

\begin{tabular}{|l|l|c|}
\hline \multicolumn{1}{|c|}{$\begin{array}{c}\text { Qualitative impact } \\
\text { assessment }\end{array}$} & \multicolumn{1}{c|}{ Quantitative impact assessment } & Impact score \\
\hline Very high & Number of invalid tests greater than 20\% & 20 \\
\hline High & Number of invalid tests between 5 and 20\% & 10 \\
\hline Moderate & Number of invalid tests between 5 and 20\% & 5 \\
\hline Low & Number of invalid tests between 1 and 5\% & 2 \\
\hline Very low & No invalid tests lower 1\% & 1 \\
\hline
\end{tabular}

\subsection{Setting the risk reference matrix}

The risk reference matrix is constructed by combining the probability and impact scales of the risk presented in Tables 1 and 2. The risk matrix can be represented both in an ordinal form (the matrix of the risk level) and in a cardinal form (the matrix of risk score) [4].

The risk score (SR) is a criterion by which the risks can be ranked and calculated as the product between the score probability of occurrence of the respective risk (SP) and the score of its impact (SI), according to the relationship 1:

$$
\mathrm{SR}=\mathrm{SP} \times \mathrm{SI} .
$$

The classification of risks is made by the values of the scores obtained (Table 4).

Table 4. Risk classification

\begin{tabular}{|l|l|l|}
\hline SR value & Risk level & Color \\
\hline $50 \leq \mathrm{SR} \leq 100$ & $5-$ Very high risk & Red \\
\hline $25 \leq \mathrm{SR} \leq 40$ & 4 - High risk & Orange \\
\hline $10 \leq \mathrm{SR} \leq 20$ & 3 - Medium risk & Yellow \\
\hline $5 \leq \mathrm{SR} \leq 8$ & 2 - Low risk & Light Green \\
\hline $1 \leq \mathrm{SR} \leq 4$ & 1 - Very low risk & Green \\
\hline
\end{tabular}

Five levels are used for risk factor scores, number correlated with probability scale and risk impact levels. For safety belt test equipment, the risks fall into four levels (Table 5).

To assess risk factors, the risk score matrix is ordered by decreasing values of the risk score.

Thus, a risk prioritization is obtained, used in the risk management documentation, which allows the necessary treatment to be established for each risk.

They are thus clearly highlighted, both the risks above the horizontal right called 'critical level' requiring treatments such as avoidance or mitigation, and the risks below the critical level that can be accepted (Figure 2). 
RECENT, Vol. 19, no. 3(56), December, 2018

Table 5. Levels of risk scores

\begin{tabular}{|c|c|c|c|c|}
\hline $\mathrm{R}_{\mathrm{i}}$ & $\begin{array}{c}\text { Probability } \\
\text { score }\end{array}$ & $\begin{array}{c}\text { Impact } \\
\text { Score/Severity }\end{array}$ & Risk score & $\begin{array}{c}\text { Risk } \\
\text { score }\end{array}$ \\
\hline $\mathrm{R} 1$ & 1 & 20 & 20 & 3 \\
\hline $\mathrm{R} 2$ & 1 & 20 & 20 & 3 \\
\hline $\mathrm{R} 3$ & 3 & 10 & 30 & 4 \\
\hline $\mathrm{R} 4$ & 1 & 20 & 20 & 3 \\
\hline R5 & 1 & 20 & 20 & 3 \\
\hline R6 & 2 & 20 & 40 & 4 \\
\hline R7 & 3 & 5 & 15 & 3 \\
\hline R8 & 1 & 20 & 20 & 3 \\
\hline R9 & 2 & 2 & 4 & 1 \\
\hline R10 & 3 & 5 & 15 & 3 \\
\hline R11 & 2 & 5 & 10 & 3 \\
\hline R12 & 3 & 10 & 30 & 4 \\
\hline R13 & 3 & 10 & 30 & 4 \\
\hline R14 & 2 & 20 & 40 & 4 \\
\hline R15 & 1 & 20 & 20 & 3 \\
\hline R16 & 2 & 10 & 40 & 4 \\
\hline R17 & 3 & 5 & 15 & 3 \\
\hline R18 & 3 & 10 & 30 & 4 \\
\hline
\end{tabular}

To assess risk factors, the risk score matrix is ordered by decreasing values of the risk score.

Thus, a risk prioritization is obtained, used in the risk management documentation, which allows the necessary treatment to be established for each risk.

They are thus clearly highlighted, both the risks above the horizontal right called 'critical level' requiring treatments such as avoidance or mitigation, and the risks below the critical level that can be accepted (Figure 2).

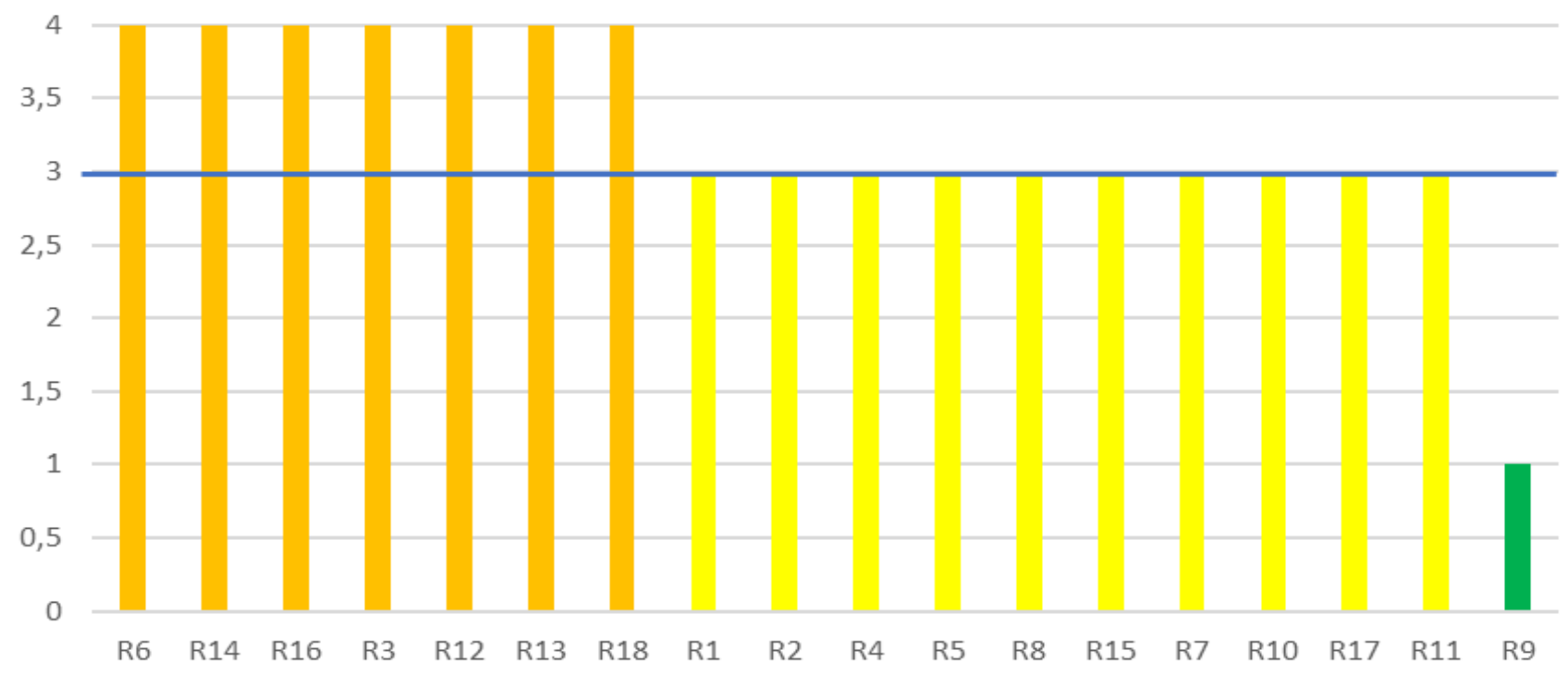

Fig. 2. Risk factors chart

\subsection{Risk treatment measures}

The main risk treatment measures may be to avoid, mitigate, transfer or accept [5].

For safety belt test equipment, risk mitigation measures are shown in Table 6. 
RECENT, Vol. 19, no. 3(56), December, 2018

Table 6. Risk treatment measures

\begin{tabular}{|c|c|c|c|c|}
\hline $\begin{array}{c}\text { Factor } \\
\text { determinant }\end{array}$ & $\mathrm{R}_{\mathrm{i}}$ & Effect & \begin{tabular}{|c|} 
Level of \\
importance
\end{tabular} & Treatment measures \\
\hline \multirow{7}{*}{ Operator } & $\mathrm{R} 1$ & Risk of injury & Medium & Operator training \\
\hline & $\mathrm{R} 2$ & Risk of injury & Medium & Personal Access Authorization \\
\hline & R3 & Invalid test & High & Test repeat \\
\hline & $\mathrm{R} 4$ & $\begin{array}{l}\text { Risk of injury, equipment } \\
\text { failure }\end{array}$ & Medium & Operator training \\
\hline & R5 & Equipment failure & Medium & Working station protection system \\
\hline & R6 & Risk of injury & High & $\begin{array}{l}\text { Existence of breaks in the work } \\
\text { programme }\end{array}$ \\
\hline & R7 & Fatigue & Medium & $\begin{array}{l}\text { Evaluation of the ergonomics of the } \\
\text { workplace }\end{array}$ \\
\hline \multirow{4}{*}{ Machine } & R8 & Additional costs & Medium & $\begin{array}{l}\text { Periodical checking of } \\
\text { equipment/recalibration }\end{array}$ \\
\hline & R9 & \begin{tabular}{|l|}
$\begin{array}{l}\text { Non-compliant working } \\
\text { conditions }\end{array}$ \\
\end{tabular} & Very low & Sound protection equipment \\
\hline & R10 & Low productivity & Medium & $\begin{array}{l}\text { Replacing components with some more } \\
\text { reliable }\end{array}$ \\
\hline & R11 & Low productivity & Medium & Evaluation and updating of machines \\
\hline \multirow{4}{*}{ Environment } & $\mathrm{R} 12$ & $\begin{array}{l}\text { Failure to comply with } \\
\text { the legislation in force }\end{array}$ & High & $\begin{array}{l}\text { Implementation of air-conditioning } \\
\text { installations }\end{array}$ \\
\hline & R13 & $\begin{array}{l}\begin{array}{l}\text { Failure to comply with } \\
\text { the legislation in force }\end{array} \\
\end{array}$ & High & $\begin{array}{l}\text { Implementation of air-conditioning } \\
\text { installations }\end{array}$ \\
\hline & R14 & Risk of injury & High & Reorganizing workplace \\
\hline & R15 & Risk of injury & Medium & Installation of lighting fixtures \\
\hline \multirow{2}{*}{ Method } & R16 & Invalid test & Medium & Redo test/Redo documentation \\
\hline & R17 & Invalid test & Medium & Operator training \\
\hline Material & R18 & Additional costs & High & Operator training \\
\hline
\end{tabular}

\section{Conclusions}

From the example shown above, it can be deduced that the probability-impact matrix is a very useful tool for risk management. This technique is often used in practice, being easy to approach, as well as helping to the management of risk events to establish those who require attention.

The risk treatment process must be followed by a monitoring and review process aimed at identifying changes in the external and internal environment, changes that may entail both the modification of risk factors and the emergence of new risks, situations that claim both a new analysis, evaluation and review of risk priorities, and the review of the treatment to be applied to them.

\section{References}

1. Bârsan-Pipu N, Popescu I. (2003): Managementul riscului: concept, metode, aplicații (Risk Management: Concepts, Methods, Applications). Editura Universității Transilvania, ISBN 973-635-180-7 (in Romanian)

2. Passenheim 0. (2013): Enterprise Risk Management. Ventus Publishing ApS, ISBN 978- 87-7681-684-1

3. Ostrom L.T., Wilhelmsen C.A. (2012): Risk Assessment: Tools, Techniques, and Their Applications. Wiley, ISBN 9780-470-89203-9

4. Olteanu F.C., Gheorghe C. (2016): Aspects regarding the qualitative analysis of risks due to the occurrence of low probability and very high impact events. Review of the Air Force Academy, ISSN 1842-9238, no. 1(31), p. 133140, http://www.afahc.ro/ro/revista/2016 1/Olteanu Gheorghe 2016 1.pdf

5. Valis D., Koucky M. (2009): Selected overview of risk assessment techniques. Problemy eksploatacji, ISSN $1232-$ 9312, 4-2009, p. 19-32, httpwww_bg_utp_edu_plartpe42009pe42009019032.pdf 